\title{
Daily Cyclic Changes in Water pH of Flooded Rice in the Mississippi Delta and Black Belt
}

\author{
Ziming Yue* and Te Ming Tseng \\ Department of Plant and Soil Sciences at Mississippi State University, USA
}

ISSN: 2637-7659

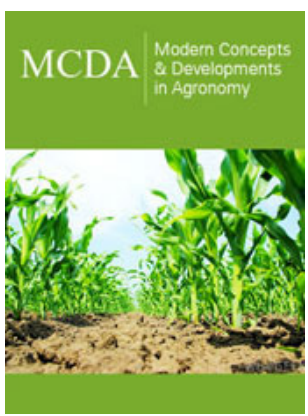

*Corresponding author: Ziming Yue, Department of Plant and Soil Sciences, Mississippi State University, USA

Submission: 啙 August 22, 2019

Published: 海 September 17, 2019

Volume 5 - Issue 1

How to cite this article: Ziming Y, Te Ming T. Daily Cyclic Changes in Water pH of Flooded Rice in the Mississippi Delta and Black Belt. Mod Concep Dev Agrono.5(2). MCDA.000606.2019.

DOI: $10.31031 /$ MCDA.2019.05.000606

Copyright@ Ziming Yue, This article is distributed under the terms of the Creative Commons Attribution 4.0 International License, which permits unrestricted use and redistribution provided that the original author and source are credited.

\section{Introduction}

Mississippi (MS) Delta is the primary rice-producing area in the state of Mississippi. The soil type in these fields (Sharkey soil), often has a $\mathrm{pH}$ of around 8.2. How does rice grow in such high soil pH? We selected two rice paddies (Figure 1) in the RR Foil Plant Science Research Center, Mississippi State University, situated on the MS Black Belt, and a soil pH of 8.2 for $\mathrm{pH}$ measurements. A cyclic $\mathrm{pH}$ change in a single day was found in the waters used for flooding the rice paddies. The RR Foil Plant Science Research Center is a 725-acre rowcrop farmland in the northeast region of Mississippi State University. It has a typical soil of the Mississippi Black Belt with Selma Chalk outcrops at its south and north boundaries. The thickness of the soil is no more than $2 \mathrm{~m}$ on the Selma chalk basement. The soil has high native fertility and usually contains carbonate particles and montmorillonite.

A pond on the farm acts a source of irrigation for the farm (Figure 1). Near the southeastern corner of the pond, two rice paddies, R1, and R2 (Figure 1) were selected for pH measurements. Besides rice, the primary weed is ducksalad. The water for flooding the rice comes from the pond and has a pH of around 9. The paddy and pond waters were sampled in $20 \mathrm{~mL}$ vials with caps at 7:30am, 12:30pm, 5:00pm, and 7:30pm in August 2019. The pHs were measured by a SympHony B10P pH meter in lab within one hour after sampling. The muddy water samples near the soil-water boundary were centrifuged, and the supernatants were decanted into $20 \mathrm{~mL}$ vials for $\mathrm{pH}$ measurements. Soil $\mathrm{pH}$ was measured following the USDA protocol [1].

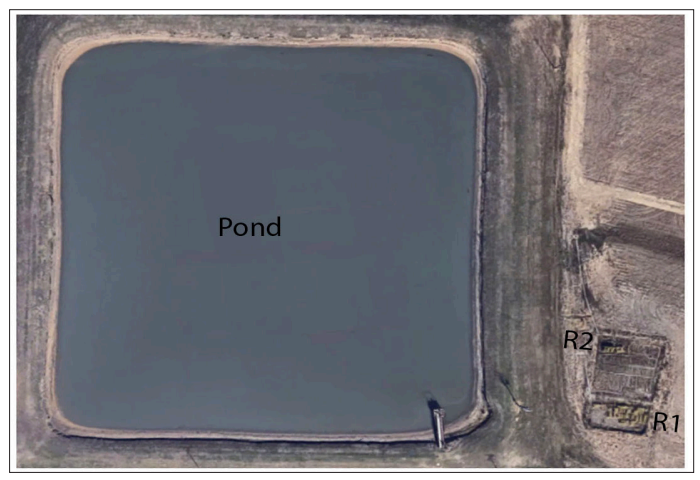

Figure 1: The irrigation pond at RR Foil Plant Science Research Center, Mississippi State University, provides water for the adjacent rice paddies, $\mathrm{R} 1$ and R2. The pond water is supplemented with groundwater with a $\mathrm{pH}$ of 8.4-8.5, and precipitation with a $\mathrm{pH} \sim 4.2$. The current pond water $\mathrm{pH}$ is around 9.

\section{Result and Discussion}

The changes in the rice paddy during the daytime (Figure 2) is generally parallel to the trend in changes in temperature during daytime; with the lowest in the morning, highest in the early afternoon, and then dropping down in the evening. This correlation might reflect the negative correlation of $\mathrm{CO}_{2}$ solubility with temperature, which is approximately linear. The highest temperature in the early afternoon leads to lowest dissolved $\mathrm{CO}_{2}$, and hence highest $\mathrm{pH}$ around the day, or vice versa. The lab measured soil $\mathrm{pH}$ was 8.2 , and the rice paddy 
flooding water came from the pond with a $\mathrm{pH}$ of around 9. The $\mathrm{pH}$ of the flooding water in the rice paddies was lower than both the soil $\mathrm{pH}$ and the original pond water $\mathrm{pH}$, except at noon when the temperature was high. The primary reason for the lowered $\mathrm{pH}$ is soil $\mathrm{CO}_{2}$ production from respiration. $\mathrm{Xu}$ et al. [2] used isotope technique and found that root-derived respiration contributed $85-92 \%$ of bulk soil respiration in rice paddy [2]. Hence, the rice and ducksalad root respiration, and minor non-rhizomicrobial respiration supplied $\mathrm{CO}_{2}$ to lower the paddy water $\mathrm{pH}$ in this case.

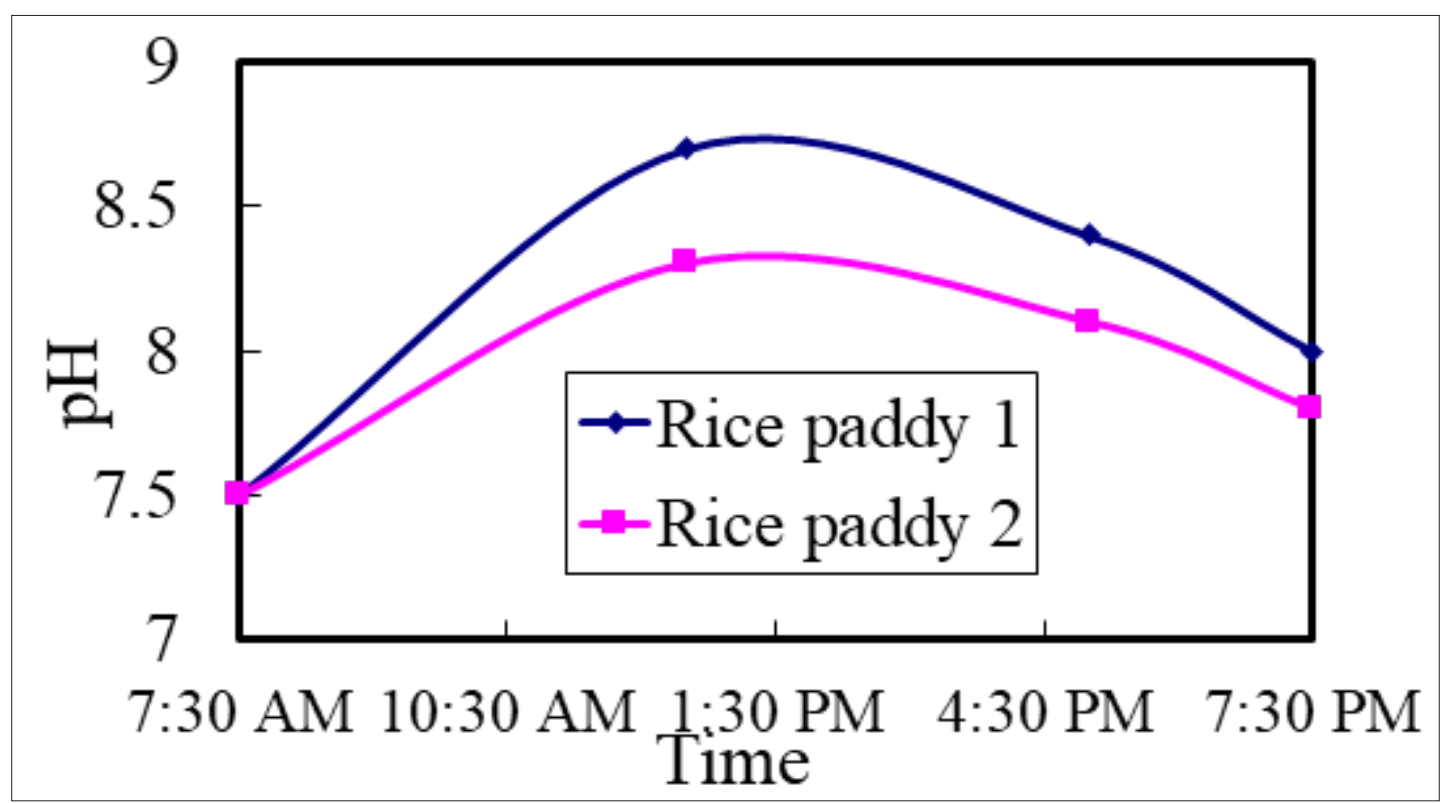

Figure 2: The $\mathrm{pH}$ of the water used for flooding the rice paddies changes in the daytime. The $\mathrm{pH}$ in both rice paddy 1 and 2 showed a similar trend, with the lowest $\mathrm{pH}$ in the morning and highest $\mathrm{pH}$ in the early afternoon, and then dropping down in the evening.

The water depth in the rice paddy was around 3 inches, with little changes in $\mathrm{pH}$ being observed along the water column. This suggests that convection along the water column is present except at the bottom. Even when the paddy water $\mathrm{pH}$ was at 8.7 around noon, the bottom water around the soil-water boundary remained at a $\mathrm{pH}$ of 7.6. The primary $\mathrm{CO}_{2}$ source was from root respiration in the soil. The transport of $\mathrm{CO}_{2}$ from roots to the water column depends on diffusion [3], which requires a $\mathrm{CO}_{2}$ concentration gradient. The hence higher $\mathrm{CO}_{2}$ concentration is expected in the rice rhizosphere. Since the lowest $\mathrm{pH}$ of paddy water was 7.45 (in the morning), the rice rhizosphere $\mathrm{pH}$ is expected to be lower than 7.45. Oh et al. [3] estimated soil $\mathrm{CO}_{2}$ concentration as 10-100 times of air $\mathrm{CO}_{2}$ concentration due to soil respiration [2]. For this case if we assume rice rhizosphere $\mathrm{CO}_{2}$ concentration as 41,000ppmv (air $\mathrm{CO}_{2}$ concentration is taken as $410 \mathrm{ppmv}$ ) and the rice rhizosphere air pressure as $1 \mathrm{~atm}$, then $\mathrm{CO}_{2}$ partial pressure $\mathrm{P}_{\mathrm{CO} 2}$ is $0.041 \mathrm{~atm}$.

The solubility product $\mathrm{K}_{\mathrm{sp}}$ of $\mathrm{CaCO}_{3}$ is taken as $10^{-8.35}$, the water autoionization constant is taken as $10^{-14}$ and the Henry's law constant $\mathrm{K}_{\mathrm{H}}$ is taken as $10^{-1.495}$. From the carbonate equilibrium, the rice rhizosphere $\mathrm{pH}$ is calculated as 6.87 . Although the highest $\mathrm{CO}_{2}$ concentration [2] is used, Oh et al. [3] referred to bulk soil $\mathrm{CO}_{2}$ concentration, and did not consider $\mathrm{CO}_{2}$ diffusion gradient around rhizosphere. Considering rice roots are the main $\mathrm{CO}_{2}$ source in this case, the rice rhizosphere in-situ pH of 6.87 is more reasonable. After 24 hours or longer in lab to reach equilibrium with air $\mathrm{CO}_{2}$, all the rice paddy waters showed a $\mathrm{pH}$ of 8.3-8.5; the pond water $\mathrm{pH}$ was 8.5-8.7. Both showed oversaturation with calcite whose equilibrium $\mathrm{pH}$ (with air $\mathrm{CO}_{2}$ ) is 8.3. This indicated that both sets of waters were potential sinks for $\mathrm{CO}_{2}$. The pond water was absorbing air $\mathrm{CO}_{2}$ as no abundant plants grew in the pond and provided $\mathrm{CO}_{2}$ from their respiration. The rice and ducksalad root respiration with minor non-rhizomicrobial respiration contributed to the $\mathrm{CO}_{2}$ levels in the paddy waters.

\section{Conclusion}

The $\mathrm{pH}$ of rice paddy flooding water was found to change in a single day with the lowest $\mathrm{pH}$ in the early morning, and the highest $\mathrm{pH}$ in the early afternoon. From carbonate equilibrium, $\mathrm{pH}$ is negatively correlated with dissolved $\mathrm{CO}_{2}$, while dissolved $\mathrm{CO}_{2}$ is controlled by temperature which is negatively correlated with $\mathrm{CO}_{2}$ solubility. Hence, the $\mathrm{pH}$ fluctuates with temperature on the same day. The paddy flooding water $\mathrm{pH}$ could be lower than the soil $\mathrm{pH}$ and the initial flooding water $\mathrm{pH}$ because of higher $\mathrm{CO}_{2}$ supply from the paddy soil than the air $\mathrm{CO}_{2}$. The primary source of the soil $\mathrm{CO}_{2}$ is rice and weed root respiration with minor non-rhizomicrobial respiration. High pH was observed around noon/high temperature because $\mathrm{CO}_{2}$ was released from water due to lower solubility. Even around noon, the $\mathrm{pH}$ at the soil-water boundary was still as low as 7.5-7.6. The in-situ $\mathrm{pH}$ of the rice rhizosphere was even lower due to higher $\mathrm{CO}_{2}$ concentration at the rhizosphere forming a diffusion gradient to the flooding water. The $\mathrm{pH}$ was possibly around 6.87 
in this case. Derivation of the rhizosphere in-situ $\mathrm{pH}$ is important because the in-situ pH is critical to rice (crop) health and yield, and it is different from the lab measured soil $\mathrm{pH}$ due to higher $\mathrm{CO}_{2}$ concentration and partial pressure.

\section{Acknowledgement}

The authors appreciate Dr. Ling Li in the Department of Biological Sciences and Dr. Zhaohua Peng in the Department of Biochemistry, Molecular Biology, Plant Pathology and Entomology at Mississippi State University for allowing us to measure pHs in their rice paddies.

\section{Conflict of Interest}

The authors declare that there is no conflict of interest.

\section{References}

1. USDA (2014) Kellogg soil survey laboratory methods manual. Soil Survey Investigations Report No. 42 Version 5.0.

2. Xu X, Kuzyakov Y, Wanek W, Richter A (2008) Root-derived respiration and non-structural carbon of rice seedlings. European Journal of Soil Biology 44(1): 22-29.

3. Oh NH, Kim HS, Richter DD (2005) What regulates soil $\mathrm{CO}_{2}$ concentrations? A modeling approach to $\mathrm{CO}_{2}$ diffusion in deep soil profiles. Environmental Engineering Science 22(1): 38-45. 
